\title{
Role of Cellulose Fibrils and Exopolysaccharides of Rhizobium leguminosarum in Attachment to and Infection of Vicia sativa Root Hairs
}

\author{
M. C. Laus, A. A. N. van Brussel, and J. W. Kijne \\ Institute of Biology Leiden, Leiden University, Wassenaarseweg 64, 2333AL Leiden, The Netherlands \\ Submitted 10 November 2004. Accepted 24 January 2005.
}

Infection and subsequent nodulation of legume host plants by the root nodule symbiote Rhizobium leguminosarum usually require attachment of the bacteria to roothair tips. Bacterial cellulose fibrils have been shown to be involved in this attachment process but appeared not to be essential for successful nodulation. Detailed analysis of Vicia sativa root-hair infection by wild-type Rhizobium leguminosarum RBL5523 and its cellulose fibril-deficient celE mutant showed that wild-type bacteria infected elongated growing root hairs, whereas cellulose-deficient bacteria infected young emerging root hairs. Exopolysaccharide-deficient strains that retained the ability to produce cellulose fibrils could also infect elongated root hairs but infection thread colonization was defective. Cellulose-mediated agglutination of these bacteria in the root-hair curl appeared to prevent entry into the induced infection thread. Infection experiments with $V$. sativa roots and an extracellular polysaccharide (EPS)- and cellulose-deficient double mutant showed that cellulose-mediated agglutination of the EPS-deficient bacteria in the infection thread was now abolished and that infection thread colonization was partially restored. Interestingly, in this case, infection threads were initiated in root hairs that originated from the cortical cell layers of the root and not in epidermal root hairs. Apparently, surface polysaccharides of $R$. leguminosarum, such as cellulose fibrils, are determining factors for infection of different developmental stages of root hairs.

In order to establish an effective root nodule symbiosis, many Rhizobium species need to be able to attach to root hairs present on the root surface of the host legume plant. In this attachment process, two steps have been distinguished (Dazzo et al. 1984). Primary attachment to the root-hair tip can be established via plant lectins, secreted at the root-hair tip, that recognize and bind specific carbohydrate structures present on the surface of the symbiotic bacteria. In addition, primary attachment can also be mediated by bacterial proteins with adhesive properties collectively called adhesins, e.g., rhicadhesin (Smit et al. 1992). Primary attachment is followed by a second attachment step involving cellulose fibrils present on the bacterial surface. This form of attachment has also been called "firm" attachment, since removal of these secondarily attached bacteria from the root surface is difficult (Ausmees et al. 1999; Dazzo et al. 1984; Smit et al. 1992). A similar two-step attachment mechanism has been described for the crown gall bacte- rium from genus Agrobacterium, also a member of the family Rhizobiaceae (Matthysse et al. 1981).

After attachment to the root-hair tip, Nod factors (lipochitin oligosaccharides) locally produced by the attached bacteria induce curling of the root-hair tip (Esseling et al. 2003). The attached bacteria become entrapped in the root-hair curl and induce the formation of an infection thread, which is a tubular structure formed by inward growth of the plant membrane. Bacteria entrapped in the root-hair curl colonize the growing infection thread, which ultimately delivers the bacteria into cortical cells of the plant root. Nod factor production by the bacteria causes the formation of a root nodule by induction of cell divisions in cortical cells of the root. The bacteria released from the infection thread colonize the nodule cells and differentiate into bacteroids, capable of fixing atmospheric nitrogen into ammonia for the benefit of the plant (Kijne 1992). Addition of Nod factors to legume roots can also result in the formation of cortical root hairs by induction of tip growth in cells of the outer cortex at the site of root nodule primordia (van Brussel et al. 1992; van Spronsen et al. 1994).

The role of rhizobial cellulose fibrils in the nodulation process did not attract much attention, the less so after demonstration that cellulose-deficient rhizobia were normally nodulating (Ausmees et al. 1999; Smit et al. 1987). Because cellulose fibrils cause persistent flocculation of many rhizobial strains, such as $R$. leguminosarum RBL5523, and because firm attachment may hamper colonization of an infection thread, cellulose fibrils may actually inhibit nodulation.

Colonization of an infection thread and nodule cells strongly depends on bacterial production of extracellular polysaccharides (EPS). Evidence is based on the observation that EPS-deficient rhizobia cannot infect root hairs. However, EPS-deficient mutants flocculate more strongly than does the wild-type strain. Agglutination of these bacteria in the infection thread was especially evident when infection thread formation was restored by coinoculation with a Nod factor-deficient strain (Laus et al. 2004). This suggests that cellulose fibril-mediated agglutination may play a role in blocking infection thread colonization of EPS-deficient strains.

In order to test this hypothesis, we constructed a $R$. leguminosarum strain defective in the production of both cellulose fibrils and EPS. Four strains, each representing one of the four possible combinations of EPS and cellulose production, were examined for attachment, infection, and nodulation of Vicia sativa subsp. nigra.

\section{RESULTS}

Mutant R. leguminosarum RBL5760 has been produced by Tn5 transposon mutagenesis and has been phenotypically 
demonstrated to lack cellulose fibrils on its surface (Smit et al. 1987). In order to identify the cause of this cellulose deficiency at the genomic level, a genomic fragment conferring kanamycin resistance was cloned. Sequencing of this genomic fragment revealed DNA sequences homologous to the celE gene of $A$. tumefaciens (Matthysse et al. 1995b). Sequences homologous to the border of the Tn5 transposon allowed determination of

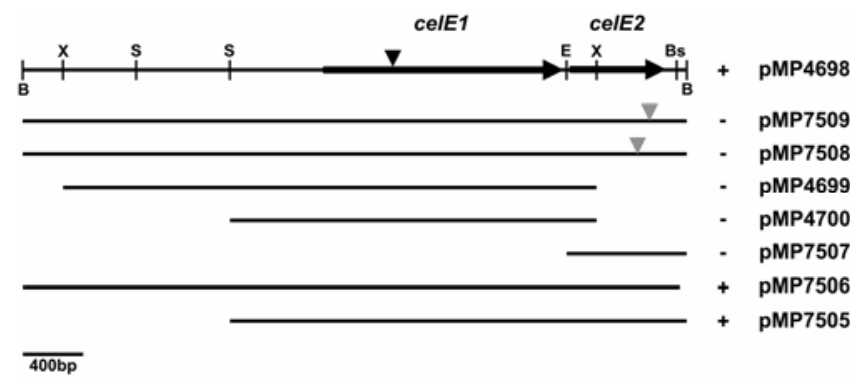

Fig. 1. The open reading frame structure of the DNA fragment able to rescue cellulose deficiency in strain RBL5760 (GenBank accession number AY876375). Beneath are the subsequent fragments and their ability to rescue cellulose deficiency in RBL5760 as indicated by + or - . The black arrowhead indicates the position of the Tn 5 transposon in the RBL5760 genome, gray arrowheads indicate the position of insertion of the Tn7 transposon. $\mathrm{B}=$ Bam HI, $\mathrm{X}=$ XhoI, $\mathrm{S}=$ SalI, E $=E c o \mathrm{RV}, \mathrm{Bs}=B s p \mathrm{EI}$ the Tn5 integration site in the RBL5760 genome, which corresponded to position $1,632 \mathrm{bp}$ downstream from the A. tumefaciens celE start codon. Homologous sequences were retrieved from the $R$. leguminosarum bv. viciae sequencing project, which enabled the design of primers for amplification of a celE-containing fragment from $R$. leguminosarum RBL5523. Introduction of this fragment on pMP4698 into the cellulose mutant RBL5760 restored cellulose production, as observed by enhanced agglutination of bacteria in liquid culture. Analysis of the rescuing DNA sequence revealed two open reading frames with homology to the celE gene of A. tumefaciens (Fig. $1)$. This open reading frame structure was identical to that of the homologous celE sequence identified in the R. leguminosarum bv. viciae sequencing project. These $R$. leguminosarum sequences share $97.5 \%$ homology within the celE operon. The celE operon of RBL5523 shares $60.0 \%$ homology to part of the A. tumefaciens celE sequence with an amino acid identity of $30.2 \%$ for the first open reading frame (celE1) and $28.8 \%$ for the second open reading frame (celE2). Sequence homology to A. tumefaciens celE is also present in the intervening sequence between the two open reading frames. Deletion of the second open reading frame either by restriction digest or Tn7 transposon integration abolished the ability to restore cellulose production in RBL5760 (Fig. 1).

To obtain EPS deficiency, we created a mutation in the pssD/E operon in an RBL5760 background. Mobilization of
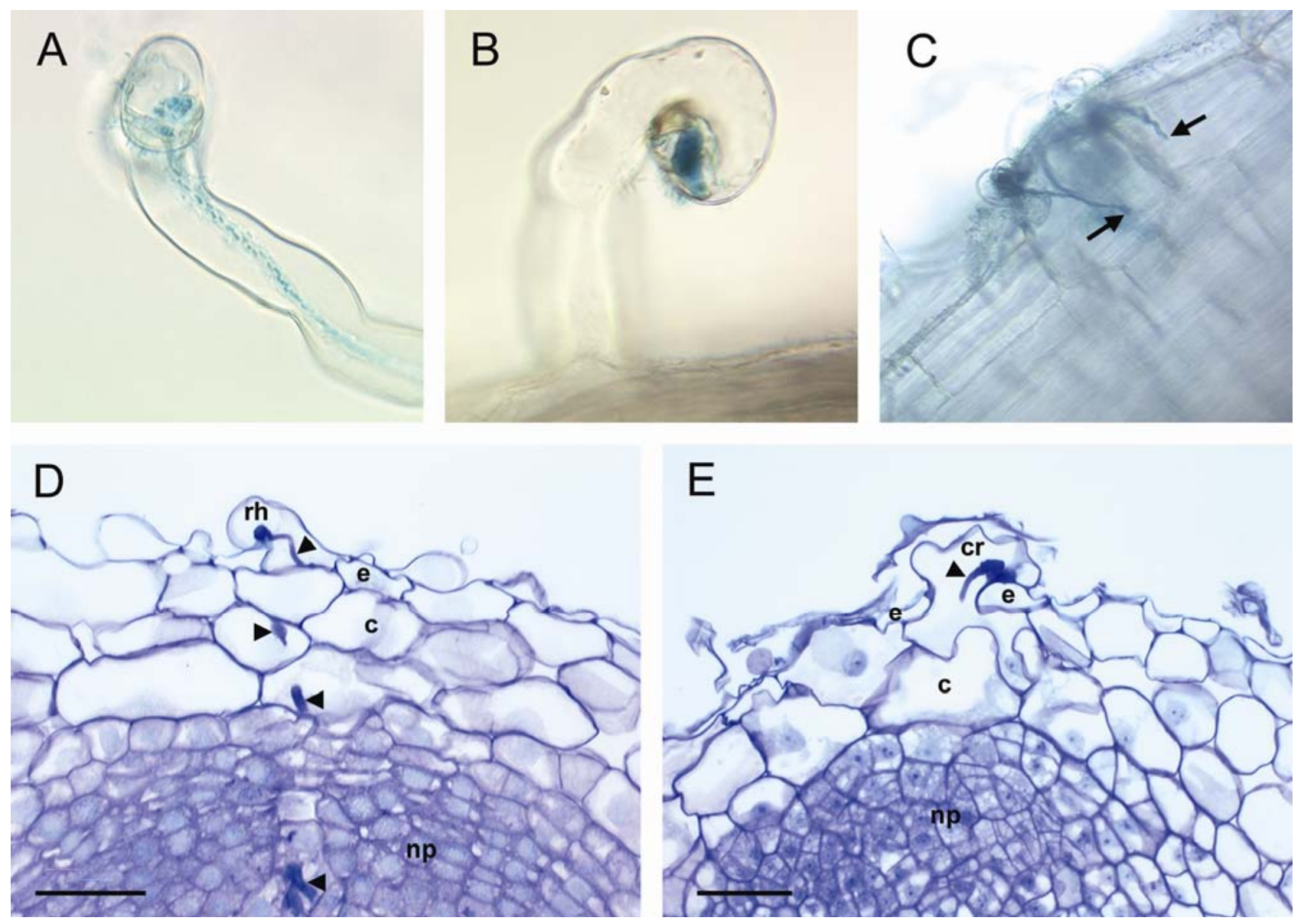

Fig. 2. Infection of Vicia sativa subsp. nigra by the Rhizobium leguminosarum strains used in this study. A, Infection of an elongated root hair by the wildtype RBL5523. B, Curling of an elongated root hair induced by the extracellular polysaccharide (EPS)-deficient RBL5833. C, Abortive infection threads induced by the EPS- and cellulose-deficient strain RBL5973. The end of the infection thread is indicated by an arrow. D, Infection of a developing nodule by the cellulose-deficient strain RBL5760. Infection thread, indicated by arrowheads, originates from a curl in a short epidermal root hair. E, Abortive infection thread induced by the EPS- and cellulose-deficient strain RBL5973. Infection thread, indicated by an arrowhead, originates in a curled cortical root hair. rh $=$ epidermal root hair, $\mathrm{cr}=$ cortical root hair, $\mathrm{e}=$ epidermis, $\mathrm{c}=$ cortical cell, and $\mathrm{np}=$ nodule primordium. The average root-hair diameter is $13 \mu \mathrm{m}$, bar represents $50 \mu \mathrm{m}$. 
pMP4695 to RBL5760 caused, in some cases, disruption of the pssD/pssE operon by integration of the green fluorescent protein (GFP)/gentamicin-resistance cassette. EPS-deficient (rough), gentamicin-resistant colonies were selected from solid agar plates and were screened for the presence of GFP luminescence and tetracycline sensitivity encoded by the pMP4695 plasmid. Furthermore, EPS-deficient colonies were selected for their inability to revert to EPS-producing strains when grown on agar plates without gentamicin selection. This resulted in the isolation of strain RBL5973, which is deficient in both cellulose fibril and EPS. EPS deficiency was confirmed by ion exchange chromatography of polysaccharides isolated from an RBL5973 liquid culture. No acidic exopolysaccharides could be eluted from the column with a sodium chloride gradient up to 1 mole. Introduction of pMP3034 (van Workum et al. 1997) containing the pssD/pssE operon into RBL5973 restored EPS production of this strain. A liquid culture of RBL5973 bacteria did not show strong flocculation of bacterial cells such as that seen with the wild-type strain RBL5523 or its EPS-deficient derivatives, such as RBL5833. Growth of RBL5973 bacteria in $\mathrm{B}^{-}$minimal medium was identical when compared with that of wild-type bacteria.

\section{Infection studies.}

First, we studied the effect of cellulose deficiency on the infection process by comparing the infection phenotypes of wild-type $R$. leguminosarum RBL5523 and the celE mutant RBL5760. Inoculation of V. sativa subsp. nigra seedlings with the wild-type bacterium RBL5523 resulted in the formation of six to seven nodules per root within seven days. Microscopic analysis of the infection process using LacZ-labeled bacteria showed that RBL5523 infects $V$. sativa roots via infection threads that originate from a curled tip of an elongated root hair (Fig. 2A). However, in about $5 \%$ of the cases, infection sites were located on the root surface and concerned short root hairs. Dividing RBL5523 bacteria entrapped in the curled tip of an elongated root hair form a focus from which an infection thread is initiated. In Vicia spp., the infection thread continues growth through the root hair and outer cortical cells towards the dividing inner cortical cells, in which the bacteria are released in the cells of the developing root-nodule primordium and develop into nitrogen-fixing bacteroids.

Inoculation of $V$. sativa roots with the cellulose-deficient but EPS-producing strain RBL5760 showed that cellulose deficiency does not affect nodule number and does not cause a delay in nodulation (Smit et al. 1987). In time, these nodules were elongated and pink colored, an indication of nitrogen fixation. Interestingly, analysis of inoculation experiments with LacZlabeled RBL5760 bacteria showed that infection of the root rarely occurred via an infection thread initiated in elongated root hairs that are present in the zone of infection. Instead, in about $95 \%$ of the cases, the infection threads originated from infection sites located on the epidermal surface. Sectioning of these roots showed that these infection sites were present at the base of short, curled root hairs with the bacteria entrapped between the root-hair tip and the epidermal cell wall (Fig. 2D). Infection threads initiated from these sites continued to grow from cortical cell layer to layer, to finally enter the nodule tissue. Restoring cellulose production by introduction of plasmid pMP4698 also restored the infection of elongated root hairs to levels observed with wild-type RBL5523.

The infection process of the cellulose- and EPS-deficient strain RBL5973 was compared with that of the strains RBL5833 and RBL5808. The latter two strains exhibit an EPS-deficient phenotype caused by Tn5 transposon insertions in the pssD gene in the case of RBL5833 and in the exo5 gene in the case of RBL5808. Nodulation phenotypes of both strains have been described in detail by van Workum and associates (1998) and by Laus and associates (2004), respectively. Roots inoculated with these EPS-deficient strains formed infection sites on both elongated root hairs (about $80 \%$ ) as well as on small root hairs on the root surface (about $20 \%$ ). Infection thread formation from these infection sites remained defective (Fig. 2B). V. sativa roots inoculated with LacZ-labeled RBL5973 bacteria, defective in both EPS and cellulose fibril production, showed the presence of abortive infection threads, which originated from infection sites on the root surface (Fig. 2C). Infection sites and infection threads were not observed in elongated root hairs. Toluidine-
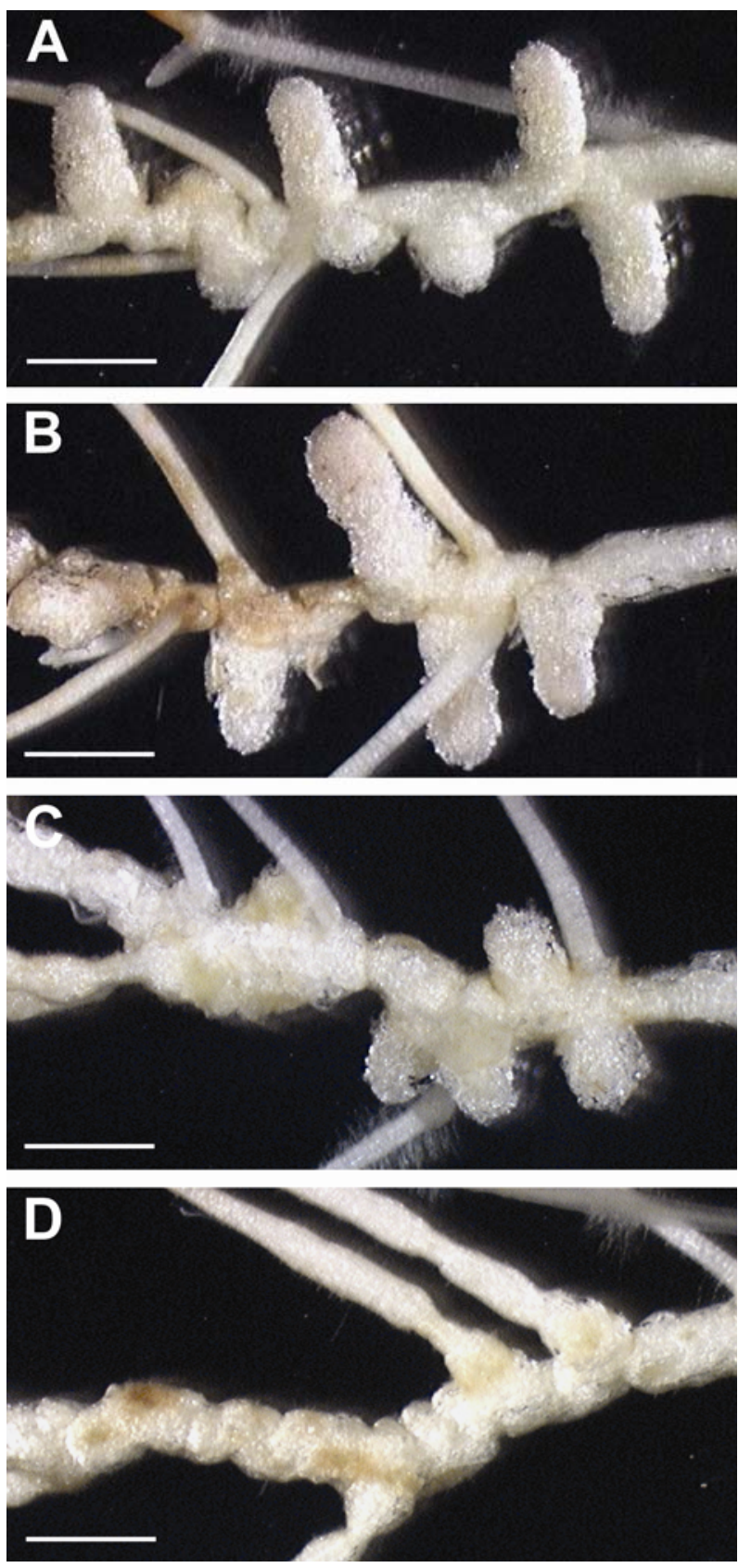

Fig. 3. Vicia sativa subsp. nigra roots ( 24 days old) inoculated with the different strains used in this study. A, Light pink and elongated nodules induced by the wild-type strain RBL5523. B, Light pink and elongated nodules induced by the cellulose fibril-deficient strain RBL5760. C, Small, white, uninfected nodules induced by the extracellular polysaccharide (EPS)and cellulose fibril-deficient strain RBL5973. D, Nodule primordia along the root surface induced by the EPS-deficient strain RBL5833, which retained the production of cellulose fibrils. Bar represents $2 \mathrm{~mm}$. 
stained sections of roots inoculated with RBL5973 bacteria showed that the initiated infection threads arose from infection sites in cortical root hairs (Fig. 2E). Presence of infected cortical root hairs was not observed on roots inoculated with other strains used in this project. Cortical root hairs developed from cells of the first or, sometimes, second cortical cell layer of the root. Due to polarized cell elongation, these cortical cells forced their way through the epidermal cell layer. Infection sites were formed by bacteria entrapped between a cortical root hair and a neighboring epidermal cell. This occurred either at the site where the cortical root hair forced its way between the epidermal cells or by curling of the cortical root hair over an adjacent epidermis cell. Infection threads initiated from these infection sites aborted in the first or second cortical cell layer, concomitant with an early arrest in nodule development. Infection of the poorly developed nodule tissue was never found. Nodules remained small, white, and uninfected when roots were observed for several weeks (Fig. 3). In contrast, RBL5833- or RBL5808inoculated roots did not show the formation of uninfected nodules; here, nodule formation was arrested at the primordium stage. Infection of the nodule tissue could not be restored by addition of purified low-molecular-weight EPS. Strain RBL5973 regained the ability to infect elongated root hairs upon introduction of the celE containing plasmid pMP4698.

In summary, wild-type cellulose- and EPS-producing rhizobia primarily infected elongated root hairs, EPS-deficient but cellulose-producing mutants started infection of elongated and short root hairs, the cellulose-deficient but EPS-producing mutant primarily infected short root hairs, whereas the celluloseand EPS-deficient mutant started infection of cortical root hairs. These results underline the importance of EPS for successful colonization of infection threads. In addition, these results suggest that bacterial cellulose fibrils are required for infection of elongated root hairs.

\section{DISCUSSION}

Cellulose deficiency of $R$. leguminosarum RBL5760 was found to be caused by a $\mathrm{Tn} 5$ insertion in the first open reading frame of an operon with homology to the celE gene in A. tumefaciens. Knockout of the second open reading frame also resulted in a lack of cellulose production in an RBL5760 background. We suggest that both open reading frames are responsible for the same step in cellulose production as celE in A. tumefaciens. In both $A$. tumefaciens and $R$. leguminosarum, the product of celE (and possibly celD) is thought to link the first UDP glucose to a lipid, hereby initiating the synthesis of a cellulose strand (Ausmees et al. 1999; Matthysse et al. 1995a). In studies of other strains, a mutation in celE has already been reported to cause cellulose fibril deficiency in both genera. For $R$. leguminosarum, the effect of cellulose deficiency on the nodulation process has never been described in detail. Persistent flocculation of strain RBL5523 and, especially, its EPSdeficient derivatives suggests constitutive expression of cellulose fibrils on the bacterial surface of this strain. As reported, EPS deficiency coincides with lack of capsular polysaccharide (CPS) production, since these two polysaccharides are similar if not identical (Laus et al. 2004). Increased flocculation of the EPS-deficient bacteria RBL5833 and RBL5808 when compared with wild-type and cellulose-deficient bacteria, suggests that EPS and CPS reduce cellulose-mediated flocculation of bacterial cells.

Root-hair curling is induced upon attachment of rhizobia to the tip of host plant root hairs. In the attachment process, a primary and a secondary form of attachment have been distin- guished. As described by Dazzo and associates (1984) and by Smit and associates (1992), cellulose fibrils play a role in the secondary, firm attachment of the bacteria to the root hair. Cellulose-deficient $R$. leguminosarum strains such as RBL5760 have been reported to lack the formation of cap-like bacterial aggregates on the root-hair tip (Ausmees et al. 1999; Smit et al. 1987). Instead, incubation of these strains with plant roots showed attachment of single bacterial cells on root hairs and the root surface.

Detailed infection studies of the wild-type bacterium RBL5523 showed the presence of infection sites in elongated root hairs. In contrast, the cellulose-deficient strain RBL5760 rarely showed infection sites present in elongated root hairs and infected the root via short curled root hairs. Infection of $V$. sativa roots by strain RBL5760 closely resembles the infection process of Bradyrhizobium japonicum on soybean, elegantly described by Turgeon and Bauer (1985). This is in agreement with data from Smit and associates (1986) who showed that $B$. japonicum strains lack cellulose-mediated cap formation on pea root-hair tips. To our knowledge, little is known about cellulose fibril production in $B$. japonicum.

Preference of the cellulose-deficient RBL5760 and RBL5973 bacteria for infection of short (cortical) root hairs suggests that cellulose-mediated firm attachment is necessary for induction of curling in the tip of an elongated root hair. Root-hair curling results from induction of tip growth by Nod factors produced by attached bacteria (van Batenburg et al. 1986). Firm attachment may be required for successful redirection of the tip growth process of root hairs in liquid medium. The average elongation rate of a growing $V$. sativa root hair has been reported to be $0.8 \mu \mathrm{m} / \mathrm{min}$ (Miller et al. 2000). During root-hair initiation, the elongation rate of the developing root hair is likely to be far less, compared with that of root hairs in full growth. Cellulose fibril-mediated attachment may be essential for infection of a fast-growing root hair, whereas primary attachment may suffice for infection of emerging root hairs. It should be noted that lectins are already present in the tip growth area of an epidermal cell even before root-hair formation (Díaz et al. 1995). Furthermore, Miller and associates (2000) have shown that the cell wall of emerging $V$. sativa root hairs is structurally different from growing root hairs. Differences in root-hair cell wall structure might add to the preference of cellulose-deficient bacteria for infection of young (cortical) root hairs.

Sections of RBL5973-inoculated roots revealed that this EPS- and cellulose-deficient strain infects the roots via cortical root hairs. Cortical root hairs can be induced by bacteria, attached to the root surface, that fail to form an infection site. Continuous Nod factor production by these bacteria is likely to induce polarized elongation of cortical cells, since cortical root hairs are mainly found on roots after application of Nod factors (van Brussel et al. 1992; van Spronsen et al. 1994). The cell wall of the newly formed root hair is the site of initiation of the infection thread induced by RBL5973. Combining EPS- and cellulose fibril-deficiency in RBL5973 partially restores infection thread colonization, as observed by the abortive infection threads. Lack of early infection-thread colonization by the EPS-deficient strains RBL5808 and RBL5833 is, therefore, likely to be caused by cellulose-mediated agglutination of the bacterial cells in the root-hair curl. This suggests that, in a wild-type situation, EPS prevents bacterial agglutination by masking the cellulose fibrils in the root-hair curl. Abortion of the RBL5973-induced infection threads before entry into the nodule primordium demonstrates the importance of EPS or CPS production for infection thread elongation. The appearance of small uninfected nodules suggests that infection of the cortex is a prerequisite 
for (young) nodule formation. This is confirmed by the observation that infection blocked inside the root hair solely results in the formation of nodule primordia.

Aggregation of bacteria inside the infection thread is also found in alfalfa roots infected with Sinorhizobium meliloti bacteria (Cheng and Walker 1998; Pellock et al. 2000). Also, in this case, aggregation was especially evident when polysaccharidedeficient $S$. meliloti bacteria were present, whereas these bacteria do not aggregate in liquid culture. Ausmees and associates (1999) suggested that plant-derived compounds can induce the formation of cellulose fibrils on the bacterial surface. In the $S$. meliloti infection process cellulose fibril production might be switched on by such plant components, hence explaining the observed bacterial aggregation inside the infection thread.

The inability of RBL5973 to infect epidermal root hairs suggests that EPS or CPS production is required for a successful interaction with developing root hairs and subsequent nodulation. Production of EPS is not essential for root-hair tip attachment of cellulose-producing strains, as judged from the formation of infection foci on $V$. sativa roots by mutants RBL5833 and RBL5808. However, van Workum and associates (1998) showed that the number of infection sites on $V$. sativa roots inoculated with RBL5833 bacteria when compared with wild type-inoculated roots is severely reduced. This suggests that EPS or CPS enhances primary attachment to the tip of growing root hairs, e.g., by cation-dependent gelation (Morris et al. 1989) and is essential for cellulose-deficient strains for infection of emerging epidermal root hairs.

\section{MATERIALS AND METHODS}

\section{Bacterial strains and plasmids.}

R. leguminosarum RBL5523 (van Workum et al. 1998) originates from $R$. leguminosarum bv. trifolii RCR5, of which the original Sym plasmid has been replaced by the bv. viciae Sym plasmid pRL1JI. The pRL1JI plasmid is marked with a Tn1831 transposon that confers spectinomycin resistance. Rifampicin and streptomycin resistance are encoded by the genome of RBL5523. RBL5833 (van Workum et al. 1997) and RBL5808 (Laus et al. 2004) originate from strain RBL5523 with a Tn5 inserted in the pssD gene and the exo5 gene, respectively. Insertion of the Tn5 transposon confers kanamycin resistance and results in an EPS-deficient phenotype in both cases. RBL5760, also identified in a Tn5 mutagenesis screen, is derived from strain RBL5523 and has been shown to lack cellulose-fibril production (Smit et al. 1987). The EPS- and cellulose-deficient strain RBL5973 has been produced by mating RBL5760 with E. coli DH5 $\alpha$ (Boyer and Roulland-Dussoix 1969) containing the suicide plasmid pMP4695 (Laus et al. 2004), according to Ditta and associates (1980). Bacterial mating took place on tryptoneyeast extract medium (Beringer 1974). Bacterial selection took place on yeast-mannitol broth medium (Hooykaas et al. 1982) containing antibiotics in the following concentrations when appropriate: kanamycin $(50 \mu \mathrm{g} / \mathrm{ml})$, spectinomycin (400 $\mu \mathrm{g} / \mathrm{ml})$, streptomycin $(500 \mu \mathrm{g} / \mathrm{ml})$, rifampicin $(20 \mu \mathrm{g}$ $/ \mathrm{ml})$, and gentamicin $(40 \mu \mathrm{g} / \mathrm{ml})$. Exopolysaccharides were isolated from the supernatant of cultures grown in $\mathrm{B}^{-}$minimal medium (van Brussel et al. 1977).

Primers OML037 (GGGATCCGTCCACGCTTCAGC) and OML39 (GGGATCCGTCGGGCGTG) were used for the amplification of the celE fragment from RBL5523 genomic DNA, followed by cloning into pBBR1-MCS5 (Kovach et al. 1995), to result in pMP4698. Plasmid pMP4698 was subjected to in vitro Tn7 transposon mutagenesis, using the GPS-1 genome priming system (New-England Biolabs, Beverly, MA, U.S.A.). Transposon insertions in the celE2 open reading frame were detected by polymerase chain reaction using OML037 and Tn7-specific primers.

\section{Polysaccharide isolation.}

Supernatant of cultures of EPS-deficient bacteria was concentrated 10-fold, was dialyzed extensively against water, was lyophilized, and was subjected to DEAE Sephadex A25 ion exchange chromatography (Amersham Biosciences, Uppsala, Sweden). The presence of hexoses in the polysaccharide fractions was determined by the orcinol-sulphuric acid method (Monsigny et al. 1988). High-molecular-weight exopolysaccharides were removed from the supernatant of RBL5523 cultures by precipitation with 3 vol of ice-cold ethanol. The ethanol was removed from the supernatant by evaporation, and the remaining supernatant was dialyzed against water and lyophilized. Acidic exopolysaccharide fractions were separated on a DEAE sephadex A25 column according to Djordjevic and associates (1986).

\section{Nodulation experiments.}

V. sativa subsp. nigra seeds were disinfected and germinated as described by van Brussel and associates (2002). Six germinated seeds were placed in a tube on top of a perforated cap of a 30-ml dark glass vial containing Jensen medium (Vincent 1970) of which the depot was removed. Bacteria were added to obtain a final number of 1,000 bacteria per milliliter, together with a final concentration of $0.1 \mathrm{mg} /$ liter aminoethoxyvinylglycine, to inhibit the formation of ethylene. The tubes were incubated in a plant growth cabinet with a temperature of $20^{\circ} \mathrm{C}, 70 \%$ relative humidity, and a 16-h-light and 8-h-dark regime. The light intensity was $220 \mu \mathrm{E} \mathrm{m}^{-2} \mathrm{~s}^{-1}$ on the table surface from Philips TLD 50W/83HF fluorescent tubes (Philips, Eindhoven, The Netherlands).

To enhance visualization of rhizobia on the root, the bacteria carried a fusion of the E. coli lacZ reporter gene to the promoter of the $S$. meliloti hemA gene (Leong et al. 1985). The staining procedure was carried out as described by Boivin and colleagues (1990) with 5-bromo-4-chloro-3-indolyl- $\beta$-D-galactopyranoside (X-gal) as a substrate. roots (6 to 7 days old) stained for LacZ were embedded in Technovit 7100 (Heraeus Kulzer, Wehrheim, Germany), according to the manufacturer's manual. Transverse serial sections $(6 \mu \mathrm{m})$ were stained using a $1 \%$ solution of toluidine blue and were investigated by light microscopy. Images were recorded with a DKC-5000 digital photo camera (Sony, Tokyo) and were corrected for brightness and contrast with Adobe Photoshop software (San José, CA, U.S.A.).

\section{ACKNOWLEDGMENTS}

This work was funded by the Netherlands Organization for Scientific Research, division of Earth and Life Sciences (NWO-ALW) code 805.18021. We thank T. Logman for her contribution to this work and C. Díaz for a critical discussion of the manuscript.

\section{LITERATURE CITED}

Ausmees, N., Jonsson, H., Höglund, S., Ljunggren, H., and Lindberg. M. 1999. Structural and putative regulatory genes involved in cellulose synthesis in Rhizobium leguminosarum bv. trifolii. Microbiology 145:1253-1262.

Beringer, J. E. 1974. R factor transfer in Rhizobium leguminosarum. J. Gen. Microbiol. 84:188-198.

Boivin, C., Camut, S., Malpica, C. A., Truchet, G., and Rosenberg, C. 1990. Rhizobium meliloti genes encoding catabolism of trigonelline are induced under symbiotic conditions. Plant Cell 2:1157-1170.

Boyer, H. W., and Roulland-Dussoix, D. 1969. A complementation analysis of the restriction and modification of DNA in Escherichia coli. J. Mol. Biol. 41:459-472.

Cheng, H. P., and Walker, G. C. 1998. Succinoglycan is required for ini- 
tiation and elongation of infection threads during nodulation of alfalfa by Rhizobium meliloti. J. Bacteriol. 180:5183-5191.

Dazzo, F. B., Truchet, G. L., Sherwood, J. E., Hrabak, E. M., Abe, M., and Pankratz, S. H. 1984. Specific phases of root hair attachment in the Rhizobium trifolii-clover symbiosis. Appl. Environ. Microbiol. 48:1140-1150.

Díaz, C. L., Logman, T. J. J., Stam, H. C., and Kijne, J. W. 1995. Sugarbinding activity of pea lectin expressed in white clover hairy roots. Plant Physiol. 109:1167-1177.

Ditta, G., Stanfield, S., Corbin, D., and Helinski, D. R. 1980. Broad hostrange DNA cloning system for gram-negative bacteria: Construction of a gene bank of Rhizobium meliloti. Proc. Natl. Acad. Sci. U.S.A. 77:7347-7351.

Djordjevic, S. P., Rolfe, B. G., Batley, M., and Redmond, J. R. 1986. The structure of the exopolysaccharide from Rhizobium sp. strain ANU280 (NGR234). Carbohydr. Res. 148:87-99.

Esseling, J. J., Lhuissier, F. G., and Emons, A. M. 2003. Nod factorinduced root hair curling: Continuous polar growth towards the point of nod factor application. Plant Physiol.132:1982-1988.

Hooykaas, P. J. J., Schnijdewindt, F. G. M., and Schilperoort, R. A. 1982. Identification of the Sym plasmid of Rhizobium leguminosarum strain 1001 and its transfer to and expression in other Rhizobia and Agrobacterium tumefaciens. Plasmid 8:73-82.

Kijne, J. W. 1992. The Rhizobium infection process. Pages 349-398 in Biological Nitrogen Fixation. G. Stacey, R. H. Burris, and H. J. Evans, eds. Chapman and Hall, London.

Kovach, M. E., Elzer, P. H., Hill, D. S., Robertson, G. T., Farris, M. A., Roop, R. M., and Peterson, K. M. 1995. Four new derivatives of the broad-host-range cloning vector pBBR1MCS, carrying different antibiotic-resistance cassettes. Gene 166:175-176.

Laus, M. C., Logman, T. J., van Brussel, A. A. N., Carlson, R. W., Azadi, P., Gao, M. Y., and Kijne, J. W. 2004. Involvement of exo5 in production of surface polysaccharides in Rhizobium leguminosarum and its role in nodulation of Vicia sativa subsp nigra. J. Bacteriol. 186:6617-6625

Leong, S. A., Williams, P. H., and Ditta, G. S. 1985. Analysis of the 5 regulatory region of the gene for $\delta$-aminolevulinic acid synthase of Rhizobium meliloti. Nucl. Acids Res. 13:5965-5976.

Matthysse, A. G., Holmes, K. V., and Gurlitz, R. H. G. 1981. Elaboration of cellulose fibrils by Agrobacterium tumefaciens during attachment to carrot cells. J. Bacteriol. 145:583-595.

Matthysse, A. G., Thomas, D. L., and White, A. R. 1995a. Mechanism of cellulose synthesis in Agrobacterium tumefaciens. J. Bacteriol. 177:1076-1081.

Matthysse, A. G., White, S., and Lightfoot, R. 1995b. Genes required for cellulose synthesis in Agrobacterium tumefaciens. J. Bacteriol. 177:1069-1075

Miller, D. D., Leferink-ten Klooster, H. B., and Emons, A. M. C. 2000. Lipochito-oligosaccharide nodulation factors stimulate cytoplasmic polarity with longitudinal endoplasmic reticulum and vesicles at the tip in vetch root hairs. Mol. Plant-Microbe Interact. 13:1385-1390.

Monsigny, M., Petit, C., and Roche, A. C. 1988. Colorimetric determination of neutral sugars by a resorcinol sulfuric acid micromethod. Anal. Biochem. 175:525-530.

Morris, V. J., Brownsey, G. J., Harris, J. E., Gunning, A. P., Stevens, B. J. H., and Johnston, A. W. B. 1989. Cation-dependent gelation of the ex- tracellular polysaccharides of Rhizobium leguminosarum: A non-specific mechanism for the attachment of bacteria to plant roots. Carbohydr. Res. 191:315-320.

Pellock, B. J., Cheng, H. P., and Walker, G. C. 2000. Alfalfa root nodule invasion efficiency is dependent on Sinorhizobium meliloti polysaccharides. J. Bacteriol.182:4310-4318.

Smit, G., Kijne, J. W., and Lugtenberg, B. J. J. 1986. Correlation between extracellular fibrils and attachment of Rhizobium leguminosarum to pea root hair tips. J. Bacteriol. 168:821-827.

Smit, G., Kijne, J. W., and Lugtenberg, B. J. J. 1987. Involvement of both cellulose fibrils and a $\mathrm{Ca}^{+}$-dependent adhesin in the attachment of $\mathrm{Rhi}$ zobium leguminosarum to pea root hair tips. J. Bacteriol. 169:4294-4301.

Smit, G., Swart, S., Lugtenberg, B. J. J., and Kijne, J. W. 1992. Molecular mechanisms of attachment of Rhizobium bacteria to plant roots. Mol Microbiol. 6:2897-2903.

Turgeon, B. G. and Bauer, W. D. 1985. Ultrastructure of infection-thread development during infection of soybean by Rhizobium japonicum. Planta 163:328-349.

van Batenburg, F. H. D., Jonker, R., and Kijne, J. W. 1986. Rhizobium induces marked root hair curling by redirection of tip growth: A computer simulation. Physiol. Plant. 66:476-480.

van Brussel, A. A. N., Planqué, K., and Quispel, A. 1977. The wall of Rhizobium leguminosarum in bacteroid and free-living forms. J. Gen. Microbiol. 101:51-56.

van Brussel, A. A. N., Bakhuizen, R., van Spronsen, P. C., Spaink, H. P., Tak, T., Lugtenberg, B. J. J., and Kijne, J. W. 1992. Induction of preinfection thread structures in the leguminous host plant by mitogenic lipo-oligosaccharides of Rhizobium. Science 257:70-72.

van Brussel, A. A. N., Tak, T., Boot, K. J. M., and Kijne, J. W. 2002. Autoregulation of root nodule formation: Signals of both symbiotic partners studied in a split-root system of Vicia sativa subsp. nigra. Mol. Plant-Microbe Interact. 15:341-349.

van Spronsen, P. C., Bakhuizen, R., van Brussel, A. A. N., and Kijne, J. W. 1994. Cell wall degradation during infection thread formation by the root nodule bacterium Rhizobium leguminosarum is a two-step process. Eur. J. Cell Biol. 64:88-94.

van Workum, W. A. T., Canter Cremers, H. C. J., Wijfjes, A. H. M., van der Kolk, C., Wijffelman, C. A., and Kijne, J. W. 1997. Cloning and characterization of four genes of Rhizobium leguminosarum bv. trifolii involved in exopolysaccharide production and nodulation. Mol. PlantMicrobe Interact. 10:290-301.

van Workum, W. A. T., van Slageren, S., van Brussel, A. A. N., and Kijne, J. W. 1998. Role of exopolysaccharides of Rhizobium leguminosarum bv. viciae as host plant-specific molecules required for infection thread formation during nodulation of Vicia sativa. Mol. Plant-Microbe Interact. 11:1233-1241.

Vincent, J. M. 1970. A manual for the practical study of root-nodule bacteria. I.B.P. handbook No. 15. Blackwell Scientific Publications, Oxford.

\section{AUTHOR-RECOMMENDED INTERNET RESOURCE}

Sanger Institute Rhizobium leguminosarum bv. viciae sequencing project: www.sanger.ac.uk/Projects/R_leguminosarum 